NBER WORKING PAPER SERIES

\title{
INTERGENERATIONAL TRANSFERS, AGING, AND UNCERTAINTY
}

David N. Weil

Working Paper No. 4477

\author{
NATIONAL BUREAU OF ECONOMIC RESEARCH \\ 1050 Massachusetts Avenue \\ Cambridge, MA 02138 \\ September 1993
}

This paper was prepared for the NBER Conference on the Economics of Aging, May 7 and 8 , 1993. I am grateful to Angus Deaton, Rachel Friedberg, Laurence Kotlikoff, Andrew Samwick, and Jonathan Skinner for helpful comments. Support for this project was provided by grant 5T32-AG00186 from the National Institute on Aging. This paper is part of NBER's research program in Aging. Any opinions expressed are those of the author and not those of the National Bureau of Economic Research. 
NBER Working Paper \#4477

September 1993

\title{
INTERGENERATIONAL TRANSFERS, AGING, AND UNCERTAINTY
}

\begin{abstract}
Research on intergenerational transmission of wealth has pointed to uncertainty -- about the date of one's own death, for example -- as a potential source of significant bequest flows. In this paper I examine the effects of this same uncertainty on the behavior of those who expect to receive bequests. Potential heirs who are prudent will consume less than would be warranted by the size of their expected bequests, and so on average consumption will rise at the age when actual bequests are received.

I examine the effect of this uncertainty on the outcome of population aging. Population aging, by changing the relative sizes of the bequeathing generation and those receiving bequests, raises the average size of bequests received and reduces the saving of the bequest-receiving generation. I show that accounting for the effects of uncertainty slows down the reduction in saving that results from population aging.
\end{abstract}

David N. Weil

Department of Economics

Box B

Brown University

Providence, R.I. 02912

and NBER 
The large wealth of the elderly, and the prospect for its transfer to a younger generation, is a subject that has attracted a large amount of attention from both economists and the popular press. ${ }^{1}$ This interest has been spurred by two factors: the increased wealth of the elderly, and changes in the ratio of the number of elderly to their children that have been part of population aging. For example, the ratio of the average net worth of households with heads aged 66-75 to the average net worth of households with heads aged 36-45 rose from 1.55 in 1962 to 2.10 in $1983 .{ }^{2}$ Similarly, the lifetime fertility rate fell from 3.14 for women born 1886-90 (those who would be leaving bequests in the 1960's) to 2.29 for those born 1906-10 (those leaving bequests in the 1980 's). ${ }^{3}$

Economists differ in their views on the importance of intergenerational flows in general, and bequests in particular, for

1 "Baby-boomers will hit an $\$ 8$ trillion inheritance jackpot, a staggering transfer of wealth that will change the nation." U.S. News and World Report (1990).

${ }^{2}$ Author's calculations based on the 1962 and 1983 Surveys of consumer finance. Net worth includes housing equity.

3 Ryder, 1986. Following the 1906-10 cohort, lifetime fertility increases gradually, reaching a peak of 3.20 for the 1931-35 cohort, and then falls dramatically to an estimated 1.92 for the 1951-55 cohort. 
the levels of saving and capital accumulation. Kotlikoff and Summers (1981) calculate that at least $80 \%$ of the wealth of those currently alive is the result of transfers (both bequests and inter vivos transfers) from previous generations. Arguing against the importance of bequests, Modigliani's (1988) rough estimate is that they constitute an annual flow of approximately one percent of wealth. But even this low estimate of the importance of bequests leaves them a significant role: assuming a wealth/income ratio of three, the size of the bequest flow is significant in comparison to the personal saving rate, which hovers around five percent.

Such a large flow of wealth should have a large effect on the behavior of those who receive it. Evaluating how changes in the size of these flows -- due, for example, to demographic change or to fiscal policy -- will affect other aspects of the economy requires proper modelling of the role of these transfers in the decisions of their recipients. A number of papers have considered how the size of these flows are affected by changes in institutions or population age structure. ${ }^{4}$ In this paper I examine the effects of the uncertainty that surrounds bequest receipt.

Uncertainty has already been incorporated into the literature on intergenerational wealth flows in several ways. Barsky, Mankiw, and Zeldes (1986) and Feldstein (1988)

${ }^{4}$ For example Hubbard and Judd (1987) or Lee (1992). 
consider intergenerational transfers in world in which there is uncertainty about future wage income, either one's own or one's children. Similarly Davies (1981) and Hurd (1989), among others, consider the role of lifespan uncertainty in generating bequests. Uncertainty about possible medical expenses at the end of life has also been cited as a motivation for the elderly to hold onto substantial resources as they age, and thus as a source of accidental bequests (Palumbo, 1991).

In this paper, I examine the importance of uncertainty on the part of the recipients of the inheritances. Uncertainty about receipt of inheritances is in large part the flip side of the uncertainty that generates bequests. The same end-of-life and medical expense uncertainties that can generate bequests will be reflected in the expectations of those who may receive an inheritance. Indeed, one would expect that the uncertainty surrounding bequest receipt (in the case of accidental bequests) could only be larger than the uncertainty which generated the bequest: in many cases, children may not really know how wealthy their parents are or the exact nature of their parents' wills.

Recent literature on consumption has stressed the role of individual uncertainty as a factor affecting decision-making (See Deaton, 1992, for a discussion). Individual uncertainty about future wages, for example, is large in comparison to aggregate 
uncertainty about future wages. Similarly, individual uncertainty about future bequest receipts may be large in comparison to uncertainty about the aggregate flow of bequests. The uncertain nature of bequest flows, combined with their large size, means that modelling consumption out of expected bequests as if there were certainty about bequest receipt will tend to overstate the effects of such expected bequests. If consumers are risk averse, then the expected utility of an uncertain bequest flow will be lower than in the case of certainty. Similarly, if consumers are "prudent" (Kimball, 1990), then the path of consumption in the case of uncertainty will differ from what would be observed in a world with certainty. Skinner (1988) shows that uncertainty about future income flows effectively increases the discount rate which is applied to their expected values. The fact that people "under consume" (from the perspective of certainty equivalence) out of expected bequests also means that consumption will, on average, rise rapidly as uncertainty about bequest receipt is resolved. Thus the expected lifetime path of consumption will slope upward more steeply than would be the case under certainty.

In this paper I examine the difference between the certainty and uncertainty models for a widely studied application: the effect of population aging on saving. Population aging, by changing the relative sizes of the bequeathing generation and 
those receiving bequests, has the potential to affect the average size of bequests received, and the saving of bequest-receiving generation. In a world with certainty equivalence, these anticipated changes in bequest flows would have immediate effects on the consumption decisions of those who expect to receive them. If uncertainty is important, by contrast, bequest flows will have their impact on consumption -- and a larger impact than under certainty -- only at the time that they are received. Since the difference between when a person can form expectations about receiving bequests and when the uncertainty about their receipt is resolved can be a full generation, allowing for uncertainty can dramatically change the timing of the effects of changes in the bequest flow.

Uncertainty also matters in evaluating the effects of changes in the annuitization of the elderly, as discussed in Auerbach, Kotlikoff, and Weil (1992). Providing annuities to the elderly reduces expected bequests -- how this affects consumption and saving of the young depends on how much the young were consuming out of these expected bequests. The immediate impact of annuitization on saving will be larger (that is, more negative) in a world where the uncertainty of bequests is taken into account than in a world of certainty equivalence. In both cases, the consumption of the elderly who receive annuities will rise. In a world of certainty, saving of the young will rise to 
partially offset the loss of the bequests, while in a world with uncertainty, the young would not initially be consuming out of expected bequests, and so would not alter their consumption much in response to a decline in expected bequests. ${ }^{5}$

The rest of this paper is organized as follows. In the next section I examine an overlapping generations model in which bequests are generated by uncertainty about one's own date of death, and in which this uncertainty is reflected in the consumption decisions of potential inheritors. I show how allowing for bequest-receipt uncertainty affects the lifetime path of consumption in both partial and general equilibrium. In Section 2, I extend the model to allow for a second uncertainty: the possibility of large end-of-life medical expenditures. Section 3 uses the model to examine the effects of population aging on saving and the level of wealth. I show that accounting for uncertainty leads to a larger adjustment of the wealth/income ratio in response to changes in population age structure than would otherwise be observed, and thus delays the effects of aging on the saving rate. Section 4 discusses the generality of the effects highlighted in this paper.

${ }^{5}$ Similarly, accounting for uncertainty in bequest receipt will change the analysis of the welfare implications of introducing annuities, as in Hubbard and Judd (1987). Uncertainty makes expected bequests less valuable, and so reduces one welfare loss from annuities that would eliminate accidental bequests. 


\section{Modelling Uncertainty in Bequest Receipt}

\subsection{Previous Work}

Hubbard and Judd (1987) consider an OLG model in which bequests are generated by end-of-life uncertainty in the absence of annuities. In their model, however, the uncertainty that generates bequests is not passed on to the next generation: all the members of a cohort receive the same bequest, which is equal to the average bequest left each year by their parents' cohort. The fact that individuals' inheritance receipt is invariant to their own family's mortality history means that all members of a birth cohort are ex-ante identical. In the models of Abel (1985) and Eckstein, Eichenbaum, and Peled (1987), by contrast, individuals receive as a bequest the actual wealth held by their parent, rather than the average wealth of the previous generation. But in these models, individuals receive bequests at birth (if they receive them at all), and so face no uncertainty about bequest receipt. Thus bequest-receipt affects the level, but not the shape, of the lifetime consumption profile. Kotlikoff, Shoven, and Spivak (1989) use a four-period model in which lifespan uncertainty generates bequests to analyze the effects of different intergenerational bargaining outcomes on the distribution of wealth. Potential heirs face uncertainty about their inheritances at the beginning life. The model I present below has a similar structure, but extends the model to 60 periods, allowing for a 
much more realistic simulation of the lifetime paths of uncertainty, bequest receipt, consumption, and wealth.

The analysis of the effects of demographic change in an overlapping generations model with bequests that is presented in this paper is similar to that of Auerbach, et. al. (1989). In that paper, there is no lifespan uncertainty, and bequests are generated directly by a "joy of giving" on the part of parents. Children receive their bequests upon their parents' deaths, but know with certainty the size of their inheritances from the beginning of life. Below I show that allowing for uncertainty in bequest receipt changes the timing of a demographic change's effect on saving.

\subsection{The Basic Model}

This section describes the basic model that will be used in the analysis. Individuals live for a maximum of 60 years. For the first 30 years of life there is no probability of dying. For the next 30 years, there is some known hazard, $p(i)$, of dying at age $i$, conditional on having reached age $i-1$. Corresponding to the set of hazards are a set of probabilities of being alive at each age $i, P(i)$. Individuals who reach age 60 know with certainty that they will die in the next period.

Families consist of a single parent and $N$ children. Children are exactly 30 years younger than their parents; Thus 
there is no chance that an individual will die before his parent. There is no altruism or annuity market in the model, and so all bequests are accidental. ${ }^{6}$ There are two uncertainties that face individuals in the model. First there is uncertainty about their own date of death. As is standard in many models, this uncertainty leads individuals to leave accidental bequests with some probability. The second uncertainty is on the part of bequest recipients: they are uncertain as to when they will receive a bequest, if at all, and how large it will be.

The model is structured so that these two uncertainties face the individual sequentially: by the end of his thirtieth year of life, an individual has completely resolved his uncertainty about bequest receipt, but has not yet resolved any uncertainty about his own date of death. As in Abel's (1985) model, the wealth that an individual inherits will be a function of not only his parent's date of death, but also of the dates of death of all of his ancestors. However, a sufficient statistic summarizing all of a family's history is the wealth of an individual at the end of his thirtieth year of life. This is all that a person's child needs to know in order to form his expectation of bequest receipt.

Throughout this paper I take the interest rate and the path

${ }^{6}$ There is also no risk sharing between generations. Such an outcome will hold in the model of Kotlikoff, Shoven, and Spivak (1989) if parents cannot credibly threaten not to leave any wealth left over at the end of their lives to their children. 
of wages as exogenous, and focus on how changes in uncertainty affect the paths of consumption, saving, and bequests.

\subsubsection{The Individual's Problem}

The individual takes as exogenous (and known from the beginning of life), a vector $\pi(\mathrm{i})$, corresponding to the probability of receiving a bequest at age $i$ given that a bequest has not yet been received, and a second vector, $b(i)$, corresponding to the size of the bequest that will be received at age $i$, given that one is received in that period. The individual is assumed to maximize the expected value of a time separable, constant relative risk aversion utility function:

$$
U=\sum_{i=1}^{60} \frac{c^{(1-\rho)}}{1-\rho}\left(\frac{1}{1+\delta}\right)^{i} P_{i}
$$

where $\delta$ is the pure rate of time discount and $P_{\mathrm{i}}$ is the probability of being alive in period $i$.

The individual's wealth (measured at the beginning of each period) evolves according to:

$$
w_{i}=(1+r) *\left(w_{i-1}+y_{i-1}-c_{i-1}\right)+D_{i} b_{i}
$$

where $y_{\mathrm{i}}$ is labor income in period $i$, and $D_{\mathrm{i}}$ is a dummy variable taking the value of one if a bequest is received in period $i$. Individuals are born with no assets, and are subject to the constraint that they cannot die in debt. 
Given that an individual has already resolved his uncertainty about receiving a bequest, it is easy to solve for the lifetime paths of wealth and consumption. The first order condition for the individual's optimization problem gives the growth rate of consumption as:

(3)

$$
c_{i+1}=c_{i} \times\left[\frac{(1+r)\left(1-p_{i+1}\right)}{1+\delta}\right]^{1 / \rho}
$$

and so consumption at age $i$ is just a function of age, wealth, and the present discounted value of future wages:

$$
c_{i}=\frac{w_{i}+\sum_{j=i}^{30} \frac{y_{j}}{(1+r)^{j-i}}}{\sum_{j=i}^{60}\left[\left(\frac{1+r}{1+\delta}\right]^{j-i} \frac{P_{j}}{P_{i}}\right]^{\frac{1}{\rho}} \frac{1}{(1+r)^{j-i}}}
$$

Given certainty about bequest receipt, it is also easy to calculate an individuals wealth path, and the path of his conditional bequest -- that is, the bequest that he will leave at each age $i$ if he dies at that age.

Solving for the individual's path of consumption when facing uncertainty about the date and size of bequest receipt is more complicated. However, because of the nature of the uncertainty, solution is not nearly as complex as many other problems involving consumption under uncertainty. Define $c^{\mathrm{nb}}(i)$ 
as the consumption at age $i$ of an individual who has not received a bequest (because his parent is still alive), and $c^{\mathrm{b}}(i)$ as consumption of an individual who has just received a bequest in period $i$. Similarly, define $w^{\text {nb }}(i)$ as the wealth of an individual who has not received a bequest, and $w^{b}(i)$ as the wealth of an individual who has just received a bequest in period $\mathrm{i}^{7}$

The wealth of an individual who receives a bequest in period $i+1$ is simply:

$$
w_{i+1}^{b}=\left(w_{i}^{n b}+y_{i}-c_{i}^{n b}\right) \times(1+r)+b_{i+1}
$$

This individual faces no future uncertainty except about his own life span: his consumption is the simple function of wealth and future wages derived above. Thus given wealth and consumption in period $i$, it is easy to calculate wealth and consumption in period $i+1$ for an individual who does receive a bequest.

It is trickier to calculate the path of consumption in the case where a bequest has not yet been received, $c^{\text {nb }}$. I take advantage of the first order condition:

Given values of $c^{\mathrm{ab}}{ }_{\mathrm{i}}$ and $c^{\mathrm{b}}{ }_{\mathrm{i}+1}$, one can use this equation to calculate the value of $c^{\mathrm{nb}}{ }_{\mathrm{i}+1}$. Thus given an initial value of $c^{\mathrm{ab}}$

${ }^{7}$ Note that $c_{i}^{b}$ and $w_{i}^{b}$ refer only to individuals who receive their bequests in period $i$ itself. Thus $c^{b}{ }_{i+1}$ is the consumption in period $\mathrm{i}+1$ of a person who received a bequest in period $i+1$, and not the consumption in period $i+1$ of a person who received a bequest in period $i$. 


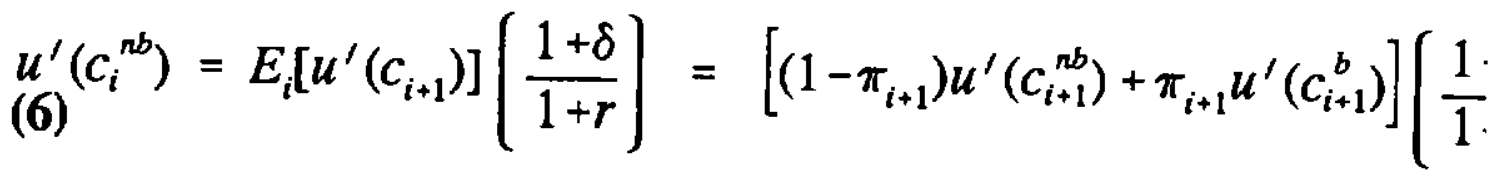

one can use the first order condition to calculate the full path of $c^{\mathrm{nb}}$. And given the paths of $c^{\mathrm{nb}}$ and $w^{\mathrm{nb}}$ up through any age $i$, it is easy to calculate the paths of wealth and consumption from date $i+1$ onward given that a bequest is received. The final step in calculating the path $c^{\mathrm{nb}}$ is to find the correct value for $c^{\mathrm{nb}}{ }_{1}$. To do this, I take advantage of the fact that $\mathrm{c}^{\mathrm{nb}}{ }_{31}$, that is, consumption at age 31 given that no bequest has been received, can be calculated two different ways. First, since there is no uncertainty about future bequests in this period, it can be calculated from the level of wealth that the individual carries into this period. Second, it can be calculated from the first order condition relating the marginal utility of consumption in adjacent periods. Only if these two values of consumption in the thirty first period match was the initial guess at $c^{\mathrm{nb}}{ }_{1}$ correct. Finding the correct value of $c^{\mathrm{nb}}{ }_{1}$ is accomplished through a simple bracketing procedure. ${ }^{8}$

${ }^{8} \mathrm{An}$ alternative way of describing the final step in the solution procedure is as follows: Given an initial value of $c^{\mathrm{nb}}$, one can use equations (4) and (6) to calculate the lifetime path of consumption for a person who never receives a bequest (noting that after age 30, the value of $\pi$ is simply zero). This path of consumption can then be checked against the lifetime budget 
Given an individual's bequest expectations, one can calculate all of the possible consumption paths that the individual may follow. Figure One illustrates some of the possible paths of individual wealth and consumption, depending on the date of bequest receipt. Wages are constant over the first 30 years of the individual's life, and zero thereafter. The wage is set so that the present value of lifetime wages is equal to 100 . The interest rate is set at five percent, and there is no time discounting. The coefficient of relative risk aversion is four. ${ }^{9}$ The conditional mortality probabilities are those for women aged 65-95 in the U.S. in 1980, from Faber (1982). The paths of bequest probabilities and conditional bequest sizes are taken from the steady state of the model in the case where there is no uncertainty about bequest receipt, which is described more fully below.

Figure One shows how consumption jumps in response to the realization of bequest receipt. Those who inherit early in life receive the most, since their parents have not run down their assets. Consumption growth for individuals who have already

constraint to see whether wealth at the end of the last possible period of life is zero. Only one initial value of $c^{\text {nb }}$ will satisfy this condition.

${ }^{9}$ Note 13 below discusses the effects of deviating from this baseline set of parameters. 
received bequests is constant until age 31 , after which rising mortality hazard reduces it and eventually leads to falling consumption. The path of consumption during the first 30 years of life for those individuals who have not received a bequest is relatively flat and may even slope downward, despite the fact that the interest rate is greater than the discount rate and there is no possibility of death over this period. The reason for this phenomenon is that people who do not receive bequests receive a negative shock in each period to their expected bequests. Both positive and negative shocks are smaller as individuals approach age 30 and the amount of wealth that their parents have available to bequeath to them falls. At the same time, however, not receiving a bequest becomes more of a surprise as individuals age and their parent's mortality hazard increases.

\subsubsection{Partial Equilibrium Effects of Uncertainty}

I begin by examining the paths of consumption and wealth for individuals with given expected bequest paths. I compare the case of certain bequest receipt with uncertainty, holding the size of the bequest flow constant. This partial equilibrium case is relevant if one wants to know how to evaluate a given level expected bequest flow. In general equilibrium, of course, the size of the expected bequest flow received by a given generation will be dependent on the uncertainty faced by their parents. Thus 
in the next section I examine the general equilibrium patterns of wealth and consumption in the certainty and uncertainty cases.

I compare consumption paths with and without uncertainty about bequest receipt, holding the expected path of bequests constant. More concretely, I compare the average consumption of a cohort of individuals each of whom faces a vector of inheritance receipt probabilities $\pi(\mathrm{i})$ and conditional inheritance sizes, $b(i)$, with the consumption path of a cohort in which each individual receives his ex-ante expected inheritance at each age. ${ }^{10}$ When bequest receipt is uncertain, the average path of consumption is just the average across different realizations of bequest receipt of the paths shown in Figure One.

The two consumption paths -- labelled "no uncertainty" and "partial equilibrium effect of uncertainty" are shown in

${ }^{10}$ There are two different ways to model the case where there is no uncertainty: first, one can give to each member of a birth cohort in each year of his life his share of the total bequest left in that year by his parent's cohort. This is equivalent to giving each member of the cohort in each year his expected bequest receipt for that year, and is the technique that I use here. Second, one can simply imagine that each individual knows the date of death (and thus the bequest) of his own parent. In terms of the cohort-average paths of consumption, saving, and wealth, these two approaches give the same results, since the propensities to consume out of a dollar of expected bequest (in the case of certainty) are invariant to the size of the bequest. Of course the two approaches have different implications for the within-cohort distribution of wealth and consumption. 
Figure Two. ${ }^{11}$ Note that in both these cases there is still uncertainty about the date of one's own death; the cases differ only in whether there is uncertainty about bequest receipt. The average level of consumption within the group that receives uncertain bequests rises more rapidly than consumption for the group with certain bequests, as individuals in the group get the news that they have received an inheritance. Put another way, uncertainty at the individual level depresses the initial level of consumption for members of this group. Members of the group that receives uncertain bequests also hold more wealth in old age as a result of their depressed initial consumption -- and thus will leave larger bequests. The next section discusses the general equilibrium effects of this difference in estates left as a function of expected inheritances received.

\subsubsection{General Equilibrium Effects of Uncertainty}

By the time an individual completes his thirtieth year, his uncertainty regarding the age of death of his parent has been resolved. As in standard models of accidental bequests, the individual chooses consumption over the rest of his life, facing only lifespan uncertainty. In choosing this path for consumption

${ }^{11}$ The bequest paths, $b(i)$ and $\pi(i)$, are those produced as steady states in the case of certain bequest receipt examined below. 
and wealth, the individual also determines a path of contingent estates, $B(i)=W(i)$. From the point of view of that individual's children, these contingent estates are a stream of contingent inheritance receipts. Given that children are exactly 30 years younger than their parents, and that each parent has $N$ children, the conditional inheritance receipt at age $i$ for an individual in family $j$ is $\mathrm{b}_{\mathrm{i}, \mathrm{j}}=B_{\mathrm{i}+30, j} / N$. Similarly, the probability of bequest receipt in each period of the child's life conditional on not having yet received a bequest is just given by his parent's mortality hazard: $\pi_{\mathrm{i}}=p_{\mathrm{i}+30}$.

At birth, individuals in a cohort differ only in the path of conditional bequests that they face. The wealth of an individual at the end of his thirtieth year of life, and thus the conditional bequest receipt path faced by that individual's children, is a function of the conditional bequest receipt path faced by the individual and of the actual date of death of the individual's parent. Thus any individual's wealth is a function of the full history of his family. The individual's wealth at the beginning of his thirty-first year, $W_{31}$, serves as a sufficient statistic to summarize all of a family's history. Considering a large population, there will be a steady state distribution of $W_{31}{ }^{12}$

12 To solve for the steady state distributions of consumption and wealth, I discretized the range of possible values of $W_{31}$. I then calculated a transition matrix between parent's value of $W_{31}$ 
The line in Figure 2 labelled "general equilibrium effect of uncertainty" shows the average path of consumption in the steady state. Because uncertainty about bequest receipt leads to a shifting of consumption to later in life, bequests are larger under uncertain bequest receipt than when bequests are certain. Thus the general equilibrium effect of uncertainty about bequest receipt is larger than the effect in partial equilibrium. The increase in expected bequests has only a minor effect on consumption early in life -- once again, as a result of prudence - and so the average lifetime consumption profile is more steeply sloped than in the partial equilibrium case. Average wealth per

and child's value of $W_{31}$; each element in the matrix corresponds to the probability that the child will have a given level of wealth for the particular level of the parent's wealth. A single row of the matrix is constructed by considering a single level of parental wealth and calculating the child's wealth for all possible dates of death of the parent. Taking this transition matrix to a high power yields a matrix in which each row is the steady state distribution of $W_{31}$. Average life cycle paths of consumption and wealth in the steady state are then calculated by combining the distribution of $W_{31}$ with all possible dates of death of the parent. This approach to finding the properties of the stochastic steady state turns out to be far more computationally efficient (and precise) than the approach of actually drawing random dates of death and then simulating over a large number of generations, as is done in Kotlikoff, Shoven, and Spivak (1989). 
capita (assuming a constant population) is $22 \%$ higher in general equilibrium when there is uncertainty about bequest receipt than when there is no such uncertainty. By contrast, the partial equilibrium effect of allowing for uncertainty about bequest receipt is to raise wealth per capita by $12 \% .{ }^{13}$

\section{Adding Uncertainty about Medical Expenditures}

In the basic model presented above, the only uncertainty facing an elderly person (who has already resolved his bequest receipt uncertainty) is about the date of his death. Among the undesirable properties of this model is that on the last possible day of life, wealth of the elderly goes down to zero. ${ }^{14}$ The

13 The values of the key parameters which produced this result were $r=5 \%, \rho=4$, and $\delta=0$. Changing a single parameter (holding the other two at their base case values) had the following effects on the ratio of wealth per capita under uncertainty to wealth per capita under certainty (which is 1.22 in the base case): lowering $\rho$ to 2 lowers the ratio to 1.15 ; lowering $r$ to .03 lowers the ratio to 1.09 ; raising $\delta$ to .03 lowers the ratio to 1.17 .

${ }^{14}$ In the model, parents run down their wealth to zero at death, and thus children face uncertainty about the size of bequests received. But note that even if parents keep the real value of wealth constant until death, there is uncertainty for the child about the present discounted value of bequest receipts. It is only when parents allow wealth to grow at the real interest rate that there is no uncertainty about the present discounted value of 
slow speed with which the elderly do run down their assets has raised the question of whether such a pattern would be observed in a world where there were a last possible day of life -- that is, whether the elderly have motivations other than their own future consumption for holding on to assets.

In this section, I extend the model by having the elderly carry wealth until death. There are several interpretations that can be put on this wealth. First, it may represent money saved for end-of-life medical expenses. More generally, the household may have some chance of entering a state in which the marginal utility of a given level of consumption rises dramatically, and may save for such an eventuality. Second, as has been well documented, the elderly hold a large fraction of their wealth in the form of houses, which are often held until death (Venti and Wise, 1990; Sheiner and Weil, 1992). ${ }^{15}$ Whether this housing wealth is held out of a desire to consume a specific bundle of housing itself, out of a desire to provide for end of life medical

inheritances on the part of the children.

${ }^{15}$ Price variability in real estate is presumably less risky from the point of view of an elderly person than from the point of view of a potential heir. Home owners are to a large extent insulated from risk from the price of their own home, since their housing cost falls in the state of the world where the asset value falls. But variation in the price of a parent's home, which may constitute most of an expected bequest, is not similarly insured. 
expenses, or as an asset shielded from Medicaid's tax, is not clear.

To be concrete, I focus on the possibility of end-of-life medical expenditures as an additional source of uncertainty facing the elderly. This modification affects the certainty of bequest receipt in two ways: first, because of health uncertainty, the elderly will carry higher assets, thus potentially leaving higher bequests. Second, the lottery over end-of-life health adds more uncertainty to bequest receipt. It also moves this uncertainty later into the child's life, and thus reduces the number of years over which shocks can be spread.

Uncertainty about medical expenditures is introduced into the basic model as follows: I assume that individuals face a constant probability, $q$, of facing extra consumption needs in the last period of life. For simplicity I hold this level of these need constant at ten years' worth of wages. Thus individuals who have a possibility of dying will always have assets greater this level. When individuals do die, their estate is equal to their total wealth with probability $(1-q)$, and to their total wealth less this emergency fund with probability $q$.

The basic model presented above can be straightforwardly extended to the case of end of life uncertainty modelled here. Once again, consumption for an individual who has resolved his uncertainty about receiving an inheritance, and who only faces 
uncertainty about his own date of death and his own end-of-life expenditures, can be written as a function of wealth, age, and future wages. The first order condition used to determine the path on consumption in the case where the parent has not yet died is:

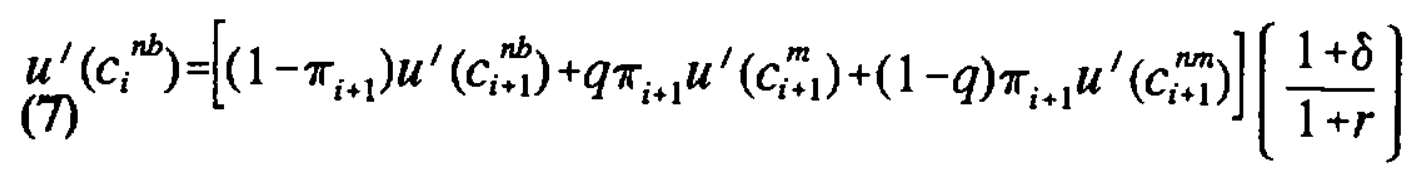

where $c_{\mathbf{i}}^{\mathrm{m}}$ is consumption in period $i$ if the individual's parent died and had end-of-life medical expenses $c_{i}^{\mathrm{mm}}$ is consumption in period $i$ if the individual's parent died and did not have such expenses.

Figure Three shows some potential realizations of the path of consumption in the model with uncertainty about end-of-life expenditures. There are now two uncertainties facing a potential heir: when his parent will die, and whether the parent will consume his emergency fund. The probability that a parent will face end-of-life expenditures $(q)$ is set at ten percent. For heirs whose parents die when they are young, there is a positive shock whether or not the parent has end-of-life expenses. For heirs whose parents die when they are old, on the other hand, having a parent who faces large end-of-life expenditures constitutes a negative shock, and consumption falls.

Figure Four shows the partial and general equilibrium 
effects of uncertainty about bequest receipt in this model. Uncertainty about one's own end-of-life needs motivates people to leave larger expected bequests in this model, and these larger bequests drive a bigger wedge between the behavior of consumption when bequest receipt is modelled as being certain and its behavior when bequest receipt is uncertain. The partial equilibrium effect is to raise consumption in the second half of life (after uncertainty about bequest receipt has been resolved) 15 percent above the level with certainty, as opposed to 9 percent in the basic model. In general equilibrium, consumption in the second half of life is 27 percent above its level with certainty, as opposed to 18 percent in the basic model.

\section{The Effects of Population Aging}

Over the next decades, the ratio of old people to working age population will be growing dramatically. Although this population aging is the product of decreases in both mortality and fertility rates, it is the latter that is by far the dominant force. (Keyfitz (1985), Weil (1993)). In changing the ratio of the elderly to their children, population aging affects either the size of bequests left, the size of bequests received, or both. In this section I consider how the effects of population aging depend on 
the level of uncertainty surrounding bequest receipt. ${ }^{16}$

\subsection{Steadv States}

I begin by comparing steady state levels of consumption and wealth (both aggregate and age profiles) for different levels of population growth and for different treatments of bequest uncertainty. Figure Five considers the four cases: with or without uncertainty about bequest receipt, and with or without uncertainty about end-of-life medical expenditures. For each case, the steady state profile of consumption is plotted for the case where each individual has 1.5 children and the case where each individual has one child (this is meant to correspond to a movement from three children per couple to two children per couple). The effect of having fewer children is to increase the size of bequests. Raising the level of bequests in turn raises the importance of uncertainty surrounding their arrival.

Increasing end-of-life uncertainty or bequest receipt uncertainty increases the impact of changing the population growth rate. Steady-state consumption at age 31 is $13 \%$ higher due to a drop in population growth when neither uncertainty is present (panel A); $25 \%$ higher when uncertainty about bequest

${ }^{16}$ The discussion here intentionally ignores the many other factors, such as changes in the youth and old-age dependency burdens, which will affect the saving rate as the population ages. 
receipt alone is present (panel B); $18 \%$ higher when uncertainty about end of life expenses alone is present (panel C); and 37\% higher when both uncertainties are present (panel D). In the cases where bequest receipt is uncertain, reducing the rate of population growth has only a small effect on initial levels of average consumption, and so induces a rapid growth rate of consumption over the course of life (as uncertainty is resolved). By contrast, when there is no uncertainty about bequest receipt, reducing the rate of population growth leads only to a parallel shift upward in the lifetime consumption profile.

These same effects can be seen in changes in assets. Reducing the rate of population growth raises the steady-state level of wealth per capita rises by $25 \%$ when neither uncertainty is present (panel A); by $40 \%$ when there is only uncertainty about bequest receipt (panel B); by $28 \%$ when only uncertainty about end-of-life expenditures is present (panel C); and by $49 \%$ when both uncertainties are present (panel D). The fact that wealth per capita rises by more in the case of uncertainty than in the case of certainty means that, as will be shown below, there is a force offsetting the negative effect of a slowdown in population growth on saving.

\subsection{Dynamic effects of aging}

I now turn to the effects on the aggregate saving rate of 
population aging. My goal is to show how allowing for uncertainty in bequest receipt alters a model's predictions for the response of saving to demographic change. I consider the following experiment: the economy is taken to be in a steady state in which each parent has 1.5 children and in which each birth cohort is $1.36 \%\left(=1.5^{1 / 30}-1\right)$ larger than the one that preceded it. Starting in year $t$, the number of births is taken to remain constant. The decline in the birth rate is taken, in turn, to be a product of some of parents in the cohort of 31-year-olds having birth rate of 1 (one child per parent), while the rest have a birth rate of 1.5. Over time, the fraction of 31-year-olds who have only one child rises until, after 30 years, all parents have a birth rate of one. Thus following the demographic transition, each birth cohort is made up of some fraction of people who have sibship ${ }^{17}$ of 1 , and some who have sibship of 1.5. After 30 years, all people born will have sibship of 1 , but people within a birth cohort will differ in the number of generations in their family since the birth rate changed: For example, of the children born 40 years after the demographic transition begins, $38 \%$ will be the second generation born with sibship of one (that is, their parents will also have had sibship of one) and $62 \%$ will be the first generation born with sibship of one (that is, their parents

\footnotetext{
${ }^{17} \mathrm{~A}$ person's "sibship" is equal to one plus the number of his siblings.
} 
will have sibship of 1.5$).^{18}$

Figure Six shows the paths of the saving rate, relative to its level in the initial steady state, for four cases considered above: with or without uncertainty about bequest receipt, and with or without uncertainty about end-of-life medical expenditures. With or without medical expenditures, allowing for uncertainty about bequest receipt delays the onset of lower saving in response to a decline in population growth. This is because, when bequest receipt is uncertain, individuals in the cohorts that will be receiving larger bequests do not immediately raise consumption in response to their larger expected bequests, but rather wait until these bequests have been received. In the forty fifth year of the demographic transition, the saving rate is equal to $30 \%$ of its initial level when there is no uncertainty about bequest receipt or end-of-life medical expenditures; $42 \%$ of its initial level when there is uncertainty about bequest receipt but not medical expenditures; $35 \%$ of its initial level when there is uncertainty about medical expenditures but not bequest receipt; and $50 \%$ of its initial level when both uncertainties are present.

${ }^{18}$ This somewhat complicated scheme is chosen to avoid the "cycling" of age group sizes that would normally be observed if the birthrate for all families jumped simultaneously, and at the same time allow for feasible computations in which only two possible levels of sibship are considered. 


\section{Extensions and Modifications}

Although the model presented above takes an important step in showing how uncertainty about bequest receipt can be incorporated into a life cycle simulation, it is still very stylized. In this section I discuss some of the ways in which the real world differs from the model, and I examine how these changes would affect the importance of the effects that are present in the model.

A first point to be noted is the low level of financial wealth held by most households. Other than a house, pension plans, and Social Security, most households in the U.S. have few assets. Given the large annuity provided by Social Security, this may be optimal behavior for households with life cycle preferences. Alternatively, it may be evidence that something like a buffer stock model of saving (Deaton, 1991; Carroll, 1992) is applicable to most households. To the extent that the degree of saving in annuitized assets is not fully under the control of the household (which is certainly true for Social Security), households with low saving will be even less prone to consume out of expected bequests than the households facing uncertainty modelled above. Households will not be able to consume out of bequests until they are received because they have no wealth to run down, and because uncollateralized borrowing is fairly limited. 
As second important consideration is the degree of uncertainty surrounding bequest. It seems clear that, among the very wealthy, although the timing of bequests is not know, the size (or more accurately, the present discounted value) of bequest receipts is not particularly uncertain. The very wealthy pass on assets at death for tax or personal reasons, not because the parents may need the money for their own consumption. Taken together these two points -- the low level of life cycle saving of most people, and unimportance of uncertainty for the wealthy -mean that uncertainty about bequest receipt is probably more important for the median household, but less important for total saving and wealth accumulation, than is implied by the model presented here.

In terms of analyzing the effects of demographic change, the model presented here has only addressed some important phenomena. The model holds constant both the average age difference between parents and children and the average age of heirs at the time that their parent dies. While the former of these is not a terrible assumption for the U.S., the latter is clearly false. In the U.S., women's life expectancy at the birth of the last child rose from 40.4 for women born 1900-1909 to 47.5 for women born 1940-49. This means that the average age of resolution of the uncertainty surrounding receipt of inheritances will have similarly risen, amplifying the effects analyzed here. 
Individuals who might fund their retirements with inheritances received from their parents may now have to wait until the time of their own retirements to see whether such inheritances are forthcoming. Prudent children faced with such a prospect will save for retirement on their own, and, on average, see their postretirement consumption rise dramatically.

Finally, a key question is how different uncertainties interact. Hubbard, Skinner, and Zeldes (1992) focus on the interaction of three sources of uncertainty that face individuals: wages, health, and date of death. In this paper I have highlighted a fourth uncertainty: the date and size of bequest receipt. If one believes that bequests are important factor in wealth accumulation, and that a significant fraction of bequests are accidental, then uncertainty about bequest receipt should be added to the list of the "usual suspects." 


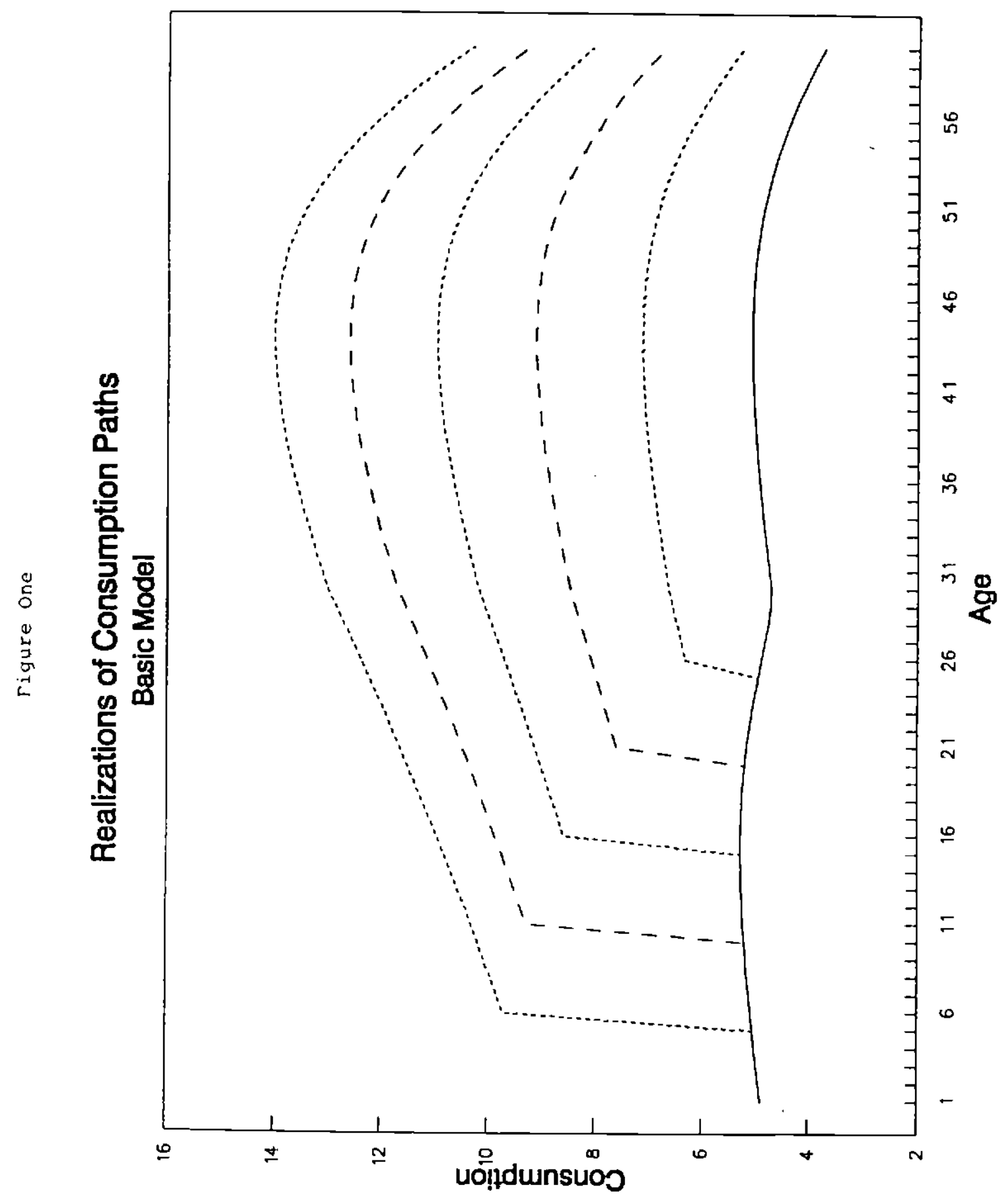




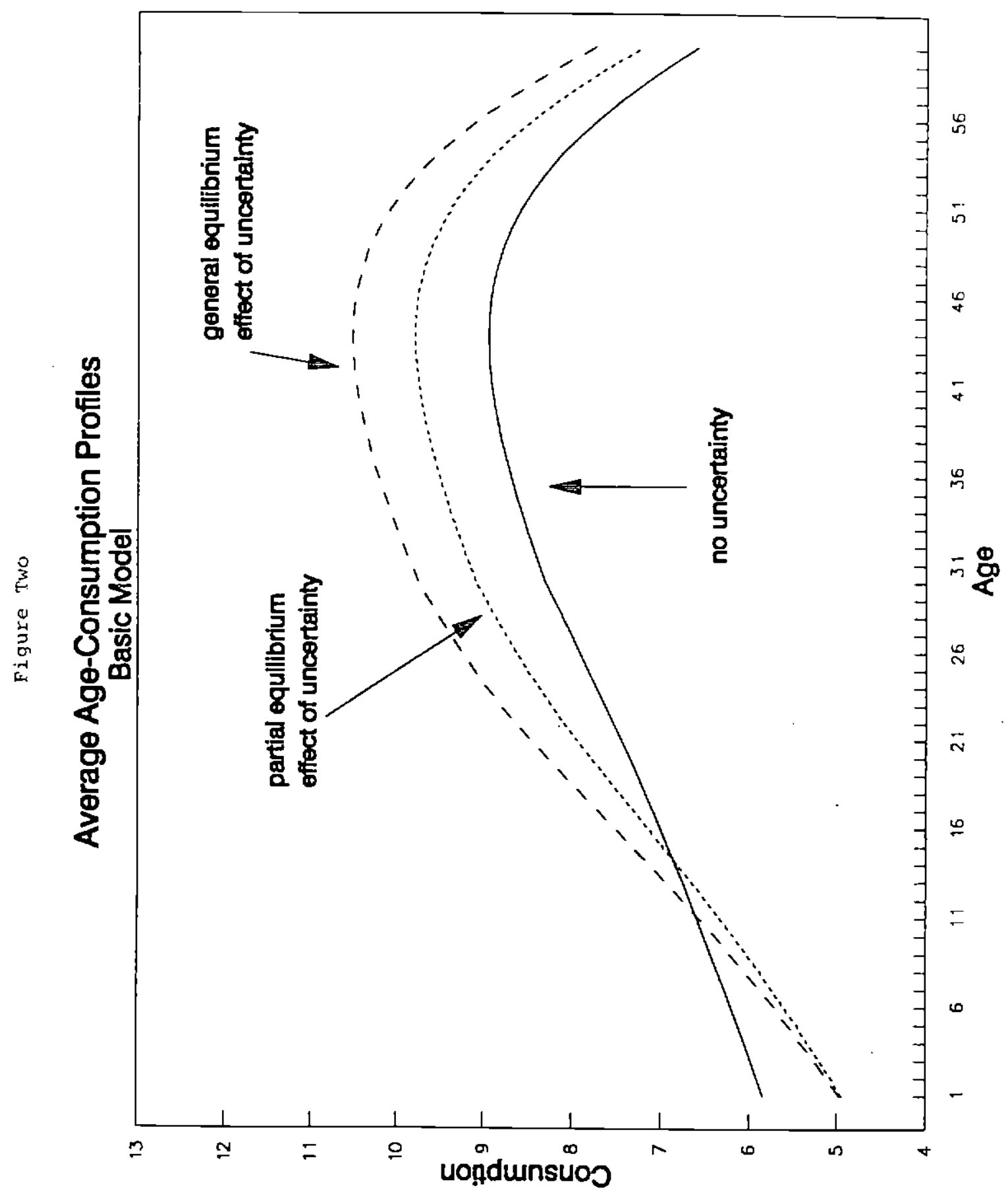




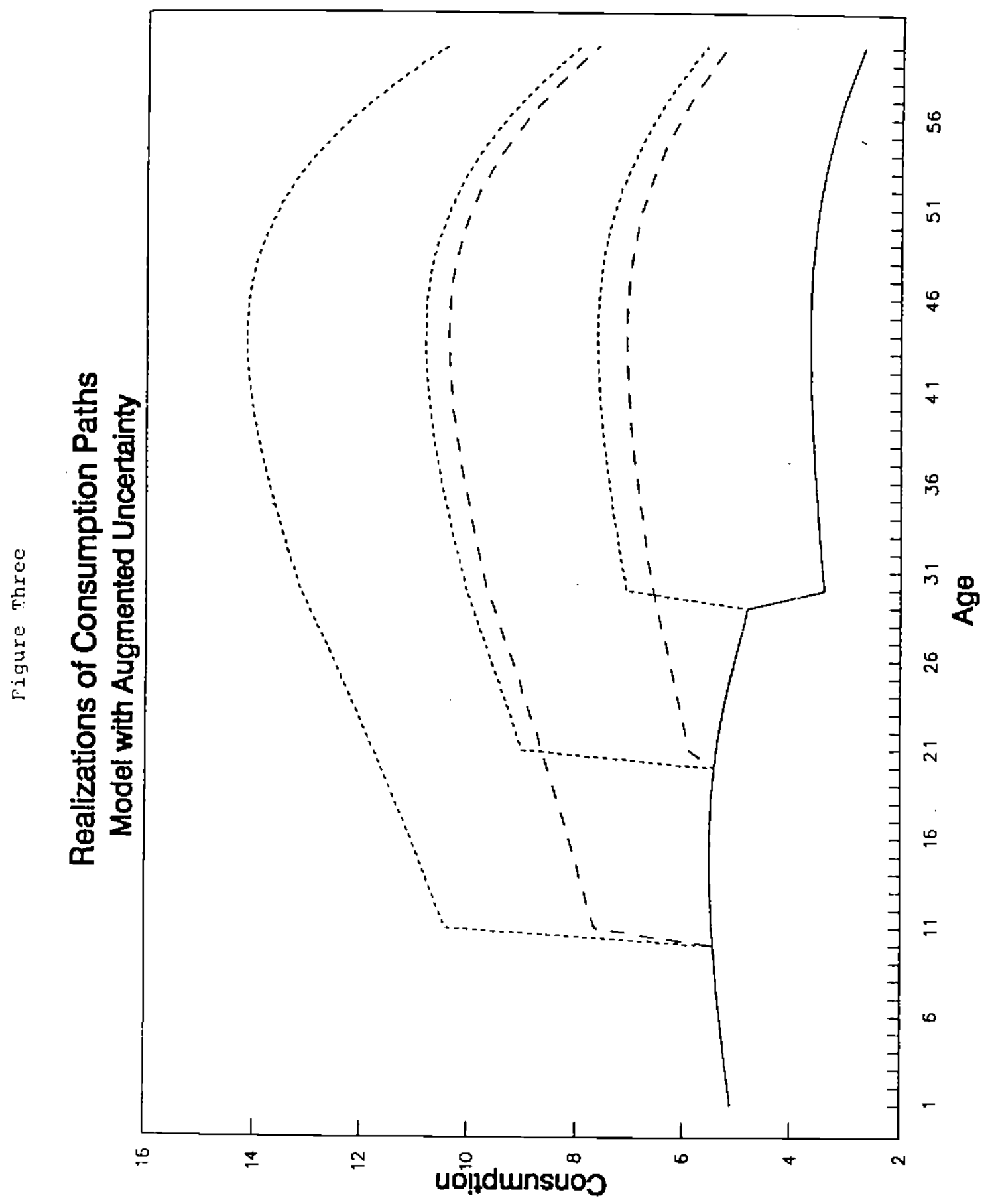




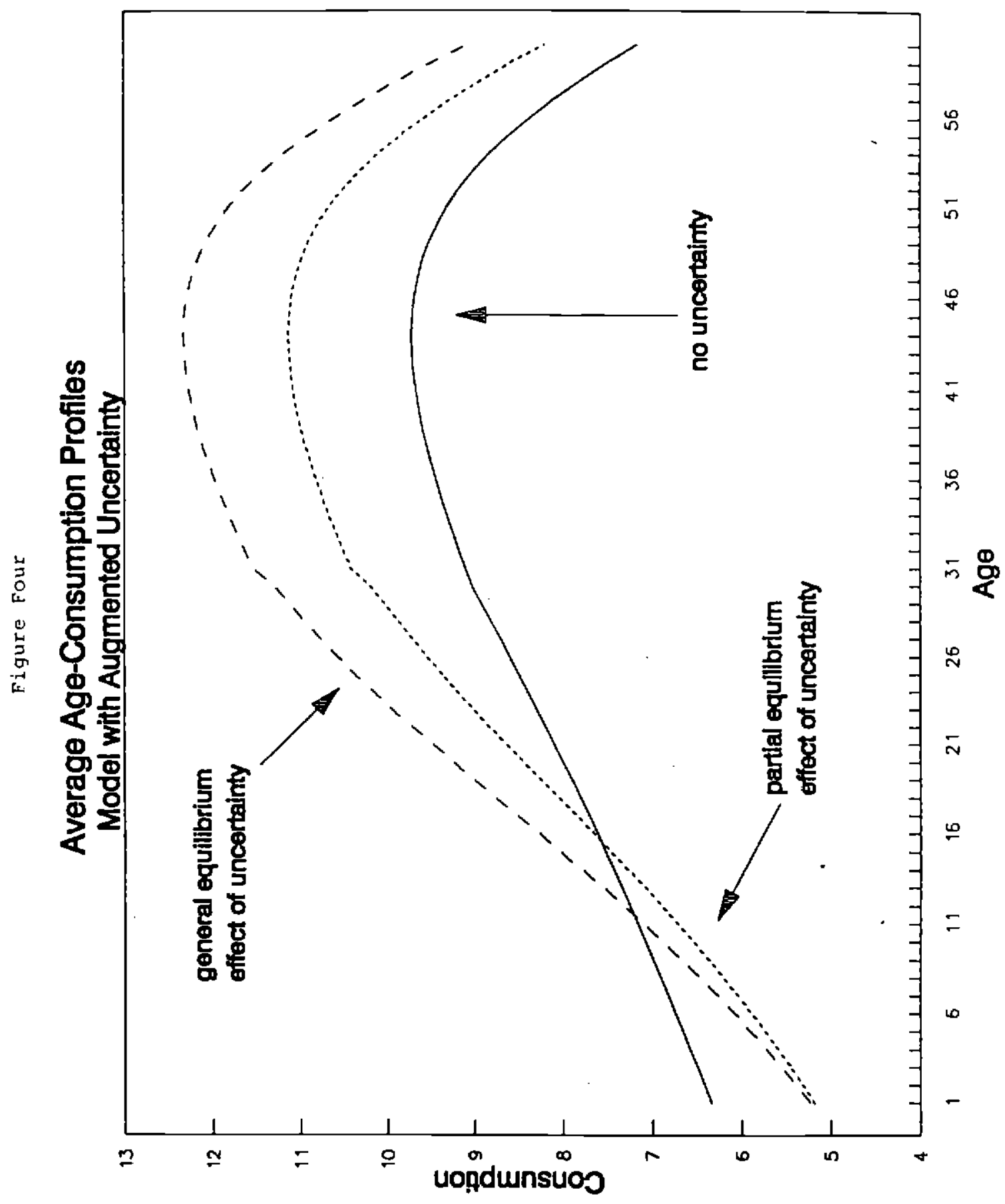



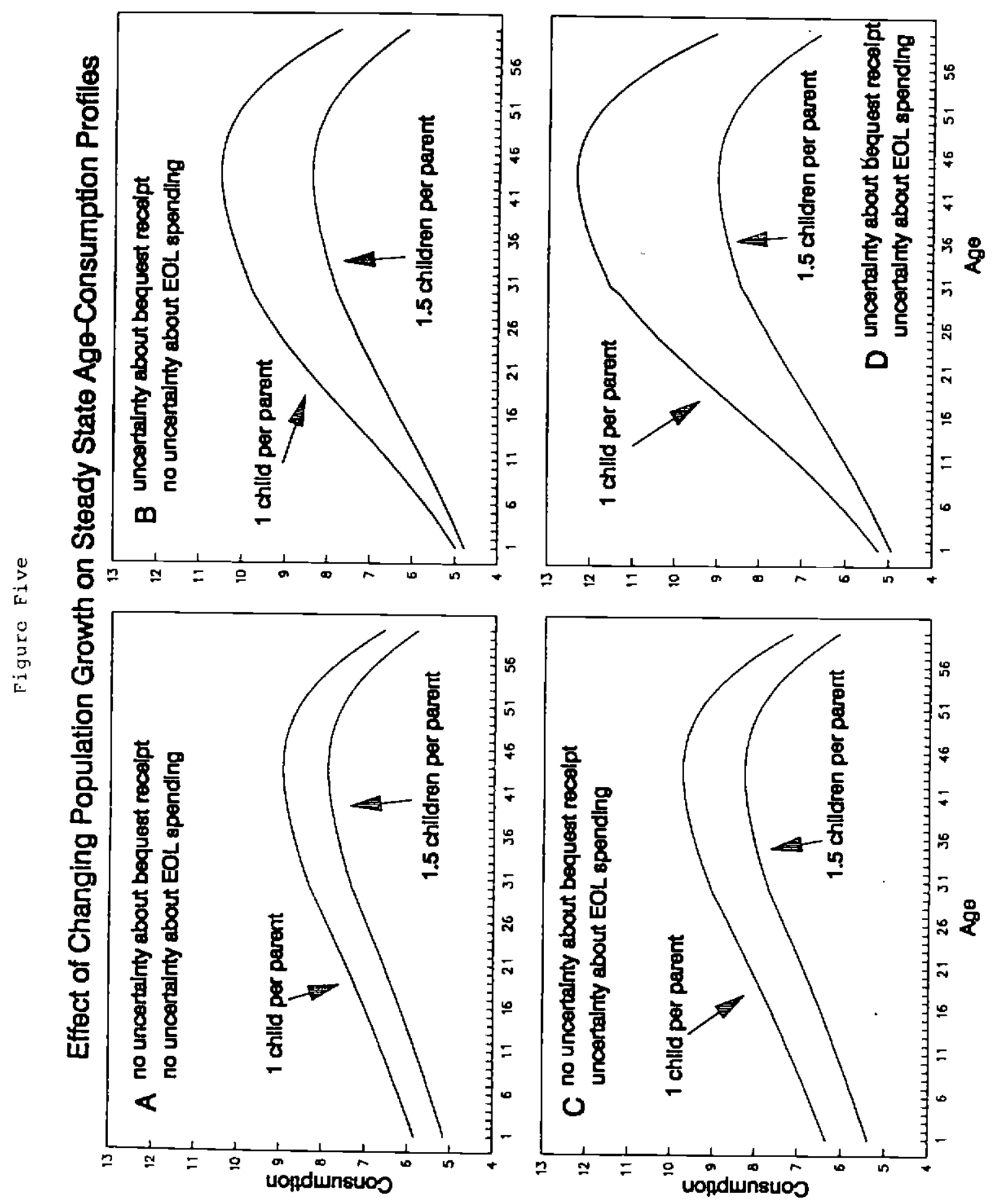


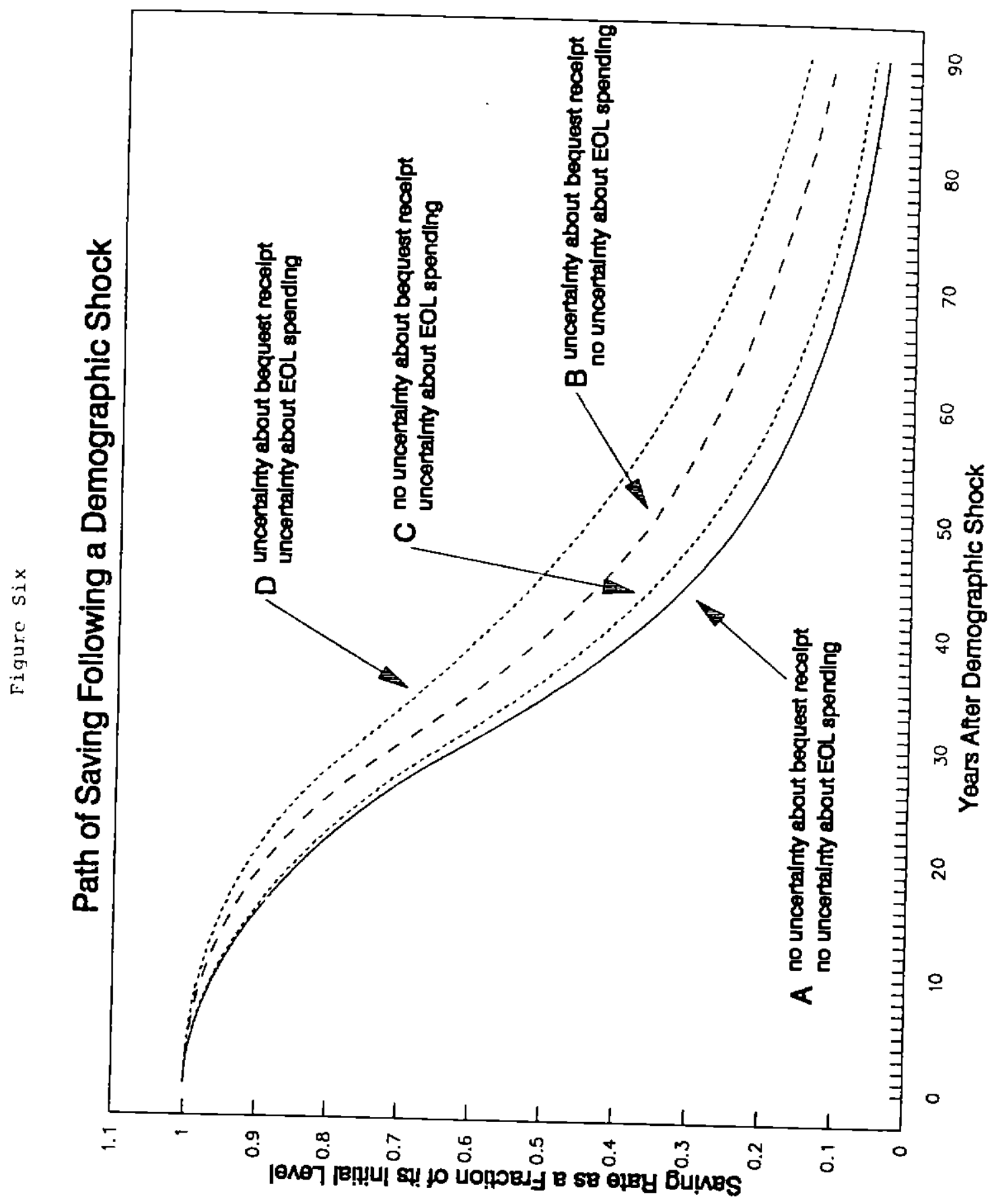

